\title{
THE TREATMENT OF BRONCHIAL ASTHMA WITH VACCINES*
}

\section{CHANDLER WAIKER, M.D.}

BOSTON

In a recent article ${ }^{1}$ it was shown that 191 , or 48 per cent., of patients with bronchial asthma were sensitive to some type of protein. In a more recent article ${ }^{2}$ the results of treatment with proteins of 100 of the sensitive patients was given; this 100 included only those patients who were sensitive to the proteins of animal hair and emanations and of food. The present paper concerns those patients who were treated with vaccines and represents a total of 178 individuals. Twenty-eight of these patients were sensitive to bacterial proteins, and therefore these patients were treated with vaccines of the organisms to which they were sensitive. The remaining 150 patients included in this paper were not sensitive to any protein with which they were tested. Since these nonsensitive patients are a part of the whole series of 400 cases, 48 per cent. of whom were found to be sensitive, it may be assumed, as shown in the previous paper, that these nonsensitive patients were tested with a sufficient number of proteins to justify the statement that they belong in the nonsensitive group. Therefore, this paper comprises all of those patients in the series of 400 studied who were sensitive to and treated with bacteria ( 28 in all), and all of those nonsensitive patients who had a reasonable amount of treatment (150 in all).

Since the aim of these studies, ${ }^{3}$ of which this article is a part, has been to determine the cause, and consequently the treatment, of bronchial asthma, the patients represented in this article have been treated in various ways; an outline of the varions methods of treatment follows. The first part of the paper concerns those patients who were sensitive to bacterial proteins, and, as already mentioned, these patients were treated with vaccines of the bacteria to which they were

* From the Medical Clinic of the Peter Bent Brigham Hospital.

1. Walker, I. C.: A Clinical Study of 400 Patients with Bronchial Asthma, Boston M. and S. J. 179:288, 1918.

2. Walker, I. C.: Treatment of Bronchial Asthma with Proteins, Archives Int. Med. 22:466, 1918.

3. Studies on bronchial asthma were made possible through a gift by $\mathrm{Mr}$. Charles F. Choate, Jr., of Boston to the Peter Bent Brigham Hospital. A complete list of the papers is given with the article in Arch. Int. Med. 22:466, 1918. 
sensitive. Since the other patients were not sensitive to proteins, they were thought to be of an infectious type and the infection was considered to be in the respiratory tract. Therefore, vaccines were made from the organisms found in the patients' sputum or nasal secretions. Since these sources produced such a wide range of bacteria, it was thought best and simplest first to find out what part those organisms which only grow on plain agar might play in the cause of bronchial asthma; the results of this work are given in the second part of the article. We were next interested in the part those organisms which grow only in dextrose bouillon and not in plain agar might play in the cause of bronchial asthma; thus, the third part of this article deals chiefly with streptococci and pneumococci. It was learned that some patients were relieved of asthma by plain agar vaccines and that others were relieved by bouillon vaccines, but still there were many in each group that were not relieved. Therefore, a series of patients were treated in both ways; that is, some who were not relieved by vaccines made from growing the sputum on plain agar were then treated with vaccines made by growing the sputum in dextrose bouillon, and vice versa; also blood agar plates were usually made from a shaken emulsion of the sputum in dextrose bouillon in order to determine the predominating organism and to identify the various types of bacteria. Thus the fourth part of the paper deals with the treatment by vaccines which were made both ways. In other papers we have already called attention to the fact that the nonsensitive as well as the sensitive patients with bronchial asthma may have asthmatic attacks throughout the year or only at various times or seasons of the year. It is obvious that it is impossible to prognosticate results from vaccine treatment in patients who have asthma only for a period of a month or six weeks once or twice a year, as is the case with some patients who have an early spring attack or a late fall attack or two such attacks; therefore, patients who have such limited asthma are not included at all in this paper, although there is evidence that bacteria are frequently the cause of such asthma. The method of treatment which has already been outlined in this paper concerns only those patients who have either continuous or frequently repeated attacks of asthma throughout the year, or those who have asthma from early fall throughout the winter and early spring; that is to say, they have asthma throughout the greater part of the year. Even in these latter cases one must be very cautious in interpreting benefit from treatment since a mild winter or an early spring might account for the improvement in the asthma, and for this reason we have attempted to be very conservative in our results. There is, however, still another type of asthma to which attention should be called since it is an entity and closely 
simulates asthma caused by pollens. This is a nonsensitive type of summer asthma caused by bacteria, and it is usually confined to the months of late May, June, July and early August, therefore closely simulating the early pollen asthma. A small series of this summer nonsenstive type of asthma will be presented in this article. Finally, attention will be called to specificity among bacteria and proteins in the treatment of bronchial asthma, and proof of such specificity, including the use of intravenous typhoid vaccine and subcutaneous peptone, will be given.

Patients sensitive to bacterial protein and treated with vaccines.As has been said, twenty-eight patients were sensitive to and treated with bacteria. In addition to these there were eleven other patients who were sensitive to bacterial proteins, but as they were also sensitive to other proteins, these patients were included in the preceding article, ${ }^{2}$ and therefore will not be discussed here. Two other patients are not discussed here because they were not seen after their first visit. Therefore, in the total of 400 patients on which these studies have been based, forty-one, or 10 per cent., were sensitive to bacterial proteins. Two different standards must be considered when reading skin tests with bacterial proteins. One type of positive reaction is an urticarial wheal measuring at least 0.25 to $0.5 \mathrm{~cm}$. in diameter, which appears within one-half hour, and the other type is a delayed reaction which occurs hours later, and the next day the site of the inoculation is inflamed, hot, and elevated, and resembles an infection.

The treatment of the twenty-eight patients who were sensitive to and treated with bacteria consisted of either stock or autogenous vaccines of those bacteria to which they were sensitive. Treatment was given with the whole killed bacteria in the form of a vaccine, because by so doing the patient would be apt both to acquire an immunity to the bacteria and become desensitized to the protein of the bacteria, whereas treatment with the protein of the bacteria alone would only desensitize and not immunize; in other words, treatment with the protein alone simply protects the patients against bacterial protein, but as the bacteria are constantly present, the infection may at any time become so great as to undo suddenly what has been accomplished in the way of desensitization. A parallel instance is that of attempting to desensitize pollen cases while the patients are being exposed to the pollen, or of attempting to desensitize a wheat case while the patient is eating wheat. Treatment with vaccines of the bacteria to which the patient is sensitive both immunizes and desensitizes at the same time; thus protection against living bacteria parallels desensitization. It seemed to make no difference whether the vaccines 
were stock or autogenous. A detailed discussion of the skin test and treatment with bacteria was presented in Studies III $^{4}$ and XIV. ${ }^{5}$

A discussion of the twenty-eight patients who were sensitive to and treated with bacteria follows. Seventeen patients were sensitive to and treated with Staphylococcus pyogenes aureus; ten were relieved of asthma, six were markedly improved and one was not benefited at all. One patient was sensitive to and relieved by treatment with both $S$, pyogenes aureus and albus. Two patients were sensitive to both $S$. pyogenes aureus and Streptococcus hemolysans, and both were relieved by treatment with $S$. hemolysans; one was markedly improved by $S$. pyogenes aureus before treatment was begun with $S$. hemolysans and the other was not treated with $S$. pyogenes aureus. One patient who was sensitive to both $S$. pyogenes aureus and diphtheroid was markedly improved by $S$. pyogenes aureus vaccine and was later relieved of asthma by diphtheroid vaccines. Two patients who were sensitive to only $S$. pyogenes albus were relieved by treatment with this organism. One patient who was sensitive to both $S$. pyogenes albus and $S$. pyogenes, was markedly improved by $S$. pyogenes albus vaccine and was later relieved of asthma by $S$. pyogenes vaccine. Three patients were sensitive to the protein of $S$. hemolysans alone, and treatment with vaccine of this organism relieved the asthma. The remaining patient in this group of twenty-eight was sensitive to both $S$. hemolysans and $S$. viridans, and treatment with vaccines of both organisms relieved the asthma. Therefore, among the twenty-eight patients who were sensitive to and treated with bacteria, there was only one failure and six others who were not relieved but were markedly improved; these seven were sensitive to and treated with $S$. pyogenes aureus. There were no failures among those who were sensitive to and treated with the other bacteria, probably because they were not so frequent. In other words, 75 per cent. of the patients who were sensitive to and treated with bacterial proteins were relieved of asthma; it is interesting that these results are the same as were obtained by the treatment of patients with other proteins to which. they were sensitive. (See previous article.)

The age of onset and the duration of asthma in the twenty-eight patients who were sensitive to and treated with bacteria follows: Three patients began to have asthma between the ages of 1 and 5 ; two of these who had had asthma for 5 and 20 years, respectively, were relieved, and the other one who was not benefited had had asthma for 7 years. Three began to have asthma between the ages of 5 and 10 ; all three were relieved and the duration of asthma in each case

4. Study III, Jour. Med. Research 35:487, 1917.

5. Study XIV, Jour. Med. Research 36:423, 1917. 
was 2, 10 and 12 years. Five patients began to have asthma between the ages of 10 and 20; one who had had asthma for only one year was markedly improved, and the other four who had had asthma for $9,13,19$ and 25 years, respectively, were relieved. Five patients began asthma between the ages of 20 and 30 ; all of these were relieved and the duration of asthma in these was $1,4,5,5$ and 10 years, respectively. Ten patients had their first attack between the ages of 30 and 40 ; the four who were markedly improved had had asthma for 1, 2, 3 and 14 years, whereas the other six patients who were relieved had had asthma for $1,1,2,9,10$ and 30 years, respectively. Only two patients in this group began to have asthma after 40 ; one who had the onset at 42 , with a duration of 3 years, was relieved, whereas the other who began to have asthma at 52, with à duration of one year, was markedly improved. Therefore, the age of onset had no bearing on the benefit from treatment, as many of those beginning to have asthma during adult life were relieved as of those who began to have asthma during childhood. Neither in these cases did the length of time which the patients had had asthma influence treatment; in fact, those who were relieved had had asthma for much longer periods than had those who were not relieved.

On comparing this group of sensitive cases with the sensitive ones presented in the preceding article it is noted that during childhood sensitization to the bacterial proteins corresponds relatively closely to those sensitive to other types of protein, but that during adult life sensitization to the bacterial proteins is relatively much more frequent than it was for other types of proteins. The duration of asthma among patients who were sensitive to the various types of proteins was relatively about the same and the percentage of cases being relieved was exactly the same for all proteins. The permanency of relief among those who were sensitive to and treated with bacteria is of much shorter duration than for those who were sensitive to and treated with animal hair proteins. With the bacterial cases relief continued for only a few months after treatment was stopped, and naturally this is all that would be expected for such a short course of treatment, together with the constant exposure to bacteria. Relief continues, however, as long as treatment is given, and in this way the bacterial cases resemble the food cases, since the food cases are free from asthma as long as those foods to which the patient is sensitive are omitted from the diet.

Nonsensitive patients treated with plain agar organisms.-Seventyfive patients were treated with vaccines made from the bacteria which were recovered from the patient's thick sputum when the sputum was streaked on large surfaces of plain agar. The various types of organisms were identified after twenty-four hours' growth, and the pre- 
dominating organism was usually made into a vaccine and given to the patient, although in some instances a stock vaccine of that particular type of organism was given instead of the autogenous vaccine, and in a few instances a combination of sputum organisms was given. Thirty-five, or 46.6 per cent., of these patients were relieved of asthma, twelve others, or 16 per cent., were greatly improved, and twenty-eight, or 37.3 per cent., were not benefited.

The types of organisms recovered from the sputum and incorporated into vaccines in these 74 patients were as follows. Of the 35 patients who were relieved of asthma, in 8 cases the vaccine comprised $S$. pyogenes aureus alone, in one case a mixture of $S$. pyogenes aureus and albus, in one case a mixture of $S$. pyogenes aureus and a gramnegative staining bacillus, ${ }^{6}$ in one case a mixture of $S$. pyogenes aureus and a diphtheroid organism, in one case $S$. pyogenes albus alone, in 17 cases a diphtheroid organism alone, in 3 cases a gram-negative staining bacillus ${ }^{6}$ alone, in one case Friedländer's bacillus alone, and in the remaining 2 cases the organism was not identified. One of the foregoing patients who was relieved by diphtheroid vaccine also had Friedländer's bacillus in large numbers, but vaccines of this organism did not improve the patient, and another of the foregoing patients who was relieved by diphtheroid vaccine was not benefited by $S$. pyogenes aureus which was also present in the sputum in large numbers; therefore, these instances show the specificity of bacteria in the treatment of asthma. Of the 12 patients who were markedly improved, 7 were treated with diphtheroid vaccines alone, 2 with a mixture of $S$. pyogenes aureus and diphtheroid, 2 with $S$. pyogenes aureus alone and 1 with the gram-negative staining bacillus. One of those who was markedly improved by diphtheroid vaccine was not benefited by $S$. pyogenes aureus vaccine, and another who was markedly improved by diphtheroid vaccine was not benefited by the gram-negative staining bacillus, thus again showing the specificity of bacteria in the treatment of asthma. The 28 patients who were not benefited were given vaccines as follows: 8 were given $S$. pyogenes aureus alone, one $S$. pyogenes aureus alone and later $S$. pyogenes albus alone, 4 were given $S$. pyogenes aureus alone and later diphtheroid alone, one a combination of $S$. pyogenes albus and diphtheroid, one $S$. pyogenes albus alone, and the remaining 13 cases were given vaccines of diphtheroid organisms alone. A summary of the results from the use of vaccines made from the several types of predominating organisms in the sputum when grown on plain agar was as follows: diphtheroid alone,

6. This gram-negative staining bacillus, which will be frequently mentioned, was more or less motile, sometimes only sluggishly motile, at other times very actively motile; in the litmus-sugar-serum waters it reacted like the colon type of bacillus although it did not produce indol in Dunham's peptone solution. 
17 relieved, 7 improved and 13 not benefited; S. pyogenes aureus alone, 8 relieved, 2 improved and 8 not benefited; $S$. pyogenes albus alone, 1 relieved and 1 not benefited; gram-negative staining bacillus, 3 relieved, 1 improved and 1 not benefited; Friedländer's bacillus, 1 relieved and 1 not benefited; since the remaining patients received a combination of bacteria in the vaccines, results cannot be attributed to any special type of organism.

The relationship between the age of onset of asthma and the results from vaccine treatment in this series of cases follows: Of those who began to have asthma between the ages of 1 and 5 years, 12 were relieved, 1 was improved and 2 were not benefited; of those whose onset of asthma began between the ages of 5 and 10 years, 5 were relieved and 2 were not benefited; of those whose onset began between the ages of 10 and 20,3 were relieved, 1 was improved and 3 were not benefited; onset between 20 and 30,3 were relieved, 7 were improved and 3 were not benefited; onset between 30 and 40, 9 were relieved, 3 were improved and 7 were not benefited; onset between 40 and 50,2 were relieved and 7 were not benefited; onset above 50, none was relieved, 8 were improved and 4 were not benefited. It is evident that three-fourths of those who began to have asthma in childhood (from 1 to 10 years) were relieved; that half of those whose onset was between the ages of 10 and 40 were relieved; that a third of those whose onset was between 40 and 50 were relieved, and that after 50 none was relieved. Therefore, in general, the younger the patient is when asthma begins the better the prognosis, and in children the prognosis is very good.

Before we prognosticate, however, we must see what effect the duration of asthma may have on the results of treatment. Of those who had had asthma for one year, 3 were relieved, 2 improved and 4 not benefited; duration for two years, none relieved, 2 improved and 3 not benefited; three years' duration, 4 relieved, 2 improved and 4 not benefited; duration four years, 3 relieved, 1 improved and 1 not benefited; five years' duration, 2 relieved and no failures; six years' duration, 3 relieved and 1 not benefited; seven years' duration, 1 relieved and 2 not benefited; eight and nine years' duration, 1 each relieved and no failures; ten, twelve and fourteen years' duration, 2 , 2 and 3 , respectively, relieved and 1,2 and 2 , respectively, not benefited; sixteen years' duration, 2 relieved and 3 not benefited; twenty to thirty years' duration, 8 relieved and 5 not benefited. In other words, of those whose duration was from 1 to 5 years, 12 were relieved and 12 were not benefited; duration from 5 to 10 years, 8 were relieved and 4 were not benefited; duration from 10 to 20 years, 7 were relieved and 9 were not benefited; duration from 20 to 30 years, 8 relieved and 
3 not benefited. Therefore, in these cases the length of time that a patient has had asthma makes little difference in the prognosis, and the duration in years of those relieved so closely parallels the duration of those not benefited that the latter serve as a good negative control for the positive results in the former.

From what has been shown in these cases it is evident that the best prognosis concerns those patients who begin to have asthma early in life and have not yet reached the age of 40 when treatment is begun, and that the worst prognosis concerns those patients who begin to have asthma late in life no matter for how short a time they have had it. In other words, the age of the patient when treatment is begun is an important fact, and the older the patient when treatment is begun the worse the prognosis. This is naturally what one would expect, because the older the patient the more liable is he to be in poor physical condition, and the poorer the patient's condition the less able is he to manufacture antibodies. Vaccines of course stimulate the production of antibodies and therefore they fail if the patient is unable to respond to their stimulus. The duration of relief from asthma in these cases also depends on the patient's ability to manufacture antibodies, and in this sense we mean resistance to disease. Some patients will remain free from asthma for months after treatment is discontinued, whereas others require the constant use of vaccines in order to be free, and when vaccines are stopped the condition quickly returns. Patients who have paroxysmal attacks of asthma, no matter how short the interval of freedom between attacks, are much easier to relieve of asthma than are those patients who have continuous asthma with no free intervals. Here again the principle of resistance enters and the fact that a patient has at times freedom from asthma means that he does have more or less resistance to the bacteria causing the trouble, and the fact that some patients have continuous asthma means that those patients never develop enough antibodies or resistance to at times temporarily recover from asthma. Therefore the prognosis in the nonsensitive asthmatic patient depends equally on the patient's resistance and on the selection of the proper vaccine for treatment.

Nonsensitive patients treated with organisms grown in dextrose bouillon.-This group of cases includes only those patients whose sputum when inoculated into dextrose bouillon grew types of organisms which resembled a streptococcus morphologically, and which, in addition, were gram-positive staining and bile insoluble. Therefore, in these cases the predominating organism when the sputum was grown in dextrose bouillon was probably a streptococcus, although no attempt was made in these instances to identify the particular type of 
streptococcus, and vaccines were made directly from the dextrose bouillon culture after from twenty to twenty-four hours' growth by centrifugalizing out the bacteria, washing in normal saline and then suspending the washed bacteria in normal saline.

A total of twenty-four patients were treated with vaccines made in this manner. Nine, or 37.5 per cent., were relieved of asthma; six, or 25 per cent., were markedly improved, and nine, or 37.5 per cent., were not benefited at all.

The preceding groups of cases were discussed in considerable detail in regard to the age of onset and duration of asthma. This last group of cases is so small in number that much space and time may be saved by the use of a table from which general conclusions may be drawn at a glance (Table 1$)$.

Table 1.-Results of Treatment of Nonsensitive Patients with Dextrose Bouillon Cultures

\begin{tabular}{|c|c|c|c|c|c|c|c|c|}
\hline \multicolumn{3}{|c|}{ Relieved of Asthma } & \multicolumn{3}{|c|}{ Markedly Improved } & \multicolumn{3}{|c|}{ Not Benefited } \\
\hline $\begin{array}{c}\text { Number } \\
\text { of } \\
\text { Patients }\end{array}$ & $\begin{array}{l}\text { Age of } \\
\text { Onset, } \\
\text { Years }\end{array}$ & $\begin{array}{c}\text { Duration } \\
\text { of Asthma, } \\
\text { Years }\end{array}$ & $\mid \begin{array}{c}\text { Number } \\
\text { of } \\
\text { Patients }\end{array}$ & $\begin{array}{l}\text { Age of } \\
\text { Onset, } \\
\text { Years }\end{array}$ & $\begin{array}{c}\text { Duration } \\
\text { of Asthma, } \\
\text { Years }\end{array}$ & $\begin{array}{c}\text { Number } \\
\text { of } \\
\text { Patients }\end{array}$ & $\begin{array}{l}\text { Age of } \\
\text { Onset, } \\
\text { Years }\end{array}$ & $\begin{array}{l}\text { Duration } \\
\text { of Asthma, } \\
\text { Years }\end{array}$ \\
\hline 1 & 1 & 20 & 1 & 1 & 25 & 1 & 4 & 60 \\
\hline 1 & 3 & 2 & . & & & 1 & 8 & 21 \\
\hline 1 & 5 & 1 & 1 & 5 & 26 & 1 & 21 & 12 \\
\hline 1 & 7 & 30 & & & & 1 & 26 & 18 \\
\hline 1 & 10 & 16 & & & & 1 & 28 & 18 \\
\hline 1 & 35 & 1 & 1 & 32 & 5 & $I$ & 30 & 20 \\
\hline 1 & 40 & 4 & $\mathbf{1}$ & 32 & 10 & 1 & 36 & 3 \\
\hline 1 & 41 & 1 & 1 & 42 & 5 & 1 & 37 & 2 \\
\hline 1 & \multirow[t]{2}{*}{39} & \multirow[t]{2}{*}{20} & 1 & 37 & 15 & 1 & 40 & 2 \\
\hline or $3 \frac{9}{7} .5 \%$ & & & $\begin{array}{c}6 \\
\text { or } 25 \%\end{array}$ & & & or $37.5 \%$ & & \\
\hline
\end{tabular}

Although the relationship in this group of cases as regards the age of onset and the duration of asthma between those who were relieved, improved and not benefited is too close to warrant definite conclusions, still the evidence is in favor of what the previous group of cases conclusively showed. Namely, that the younger the patient is when asthma began, irrespective of the duration, the better the prognosis, and that the older the patient is when asthma begins, no matter how short a time he has had asthma, the poorer the prognosis. The permanency of relief in the patients treated with streptococcus vaccines does not seem to differ from that in those treated as previously outlined in this paper.

Nonsensitive patients treated with several different vaccines.-The patients in this group were not only treated with the predominating 
organism in their sputum when it was grown on plain agar and in dextrose bouillon, but also, if the patient was not relieved by such vaccines, other types of organisms were employed. In other words, different types of vaccines were tried, each one for 'a period of several weeks, until the proper one was found and relief or marked improvement resulted. Since, as already shown in this paper, of the organisms which were recovered from plain agar, the diphtheroid and $S$. pyogenes aureus usually predominated and were found to give relief most frequently, and of the organisms which were recovered from dextrose bouillon, the streptococci usually predominated and were found to give relief most frequently, these were the first to be tried and consequently they were used in most instances. When these failed, other organisms were used, so that in the cases which were not relieved at all, many different types of vaccines were employed. This method of treatment in these cases does not show the relative merits of growing bacteria for vaccines on any special kind of mediums, but it does show clearly the specificity of bacteria in the treatment of bronchial asthma.

Thirty-five patients were treated as outlined in the foregoing. Eleven, or 31.4 per cent., were relieved; 8 , or 23 per cent., were markedly improved, and 16 , or 45.6 per cent., were not benefited at all.

Of the eleven patients who were relieved, one was relieved by diphtheroid vaccines after streptococci had failed, one was relieved by a mixture of $S$. pyogenes aureus and albus after streptococci had failed; four were felieved by streptococci after diphtheroid vaccines had failed, and in one of these $S$. pyogenes aureus had also failed; the remaining five patients were relieved by $S$. hemolysans vaccines after diphtheroid vaccines had failed, and in three of these $S$. pyogenes aureus vaccine had also failed.

Of the eight patients who were markedly improved, two were markedly improved by diphtheroid vaccines after streptococci and $S$. pyogenes aureus vaccines had failed; one was markedly improved by streptococcus vaccines after diphtheroid vaccines had failed, and the remaining five patients were markedly improved by $S$. hemolysans vaccines after diphtheroid vaccines had failed, and in three of these $S$. pyogenes aureus vaccines and in another $S$. albus vaccine had also failed.

The sixteen patients who were not benefited were treated with the following types of vaccines: 13 with diphtheroids, 12 with streptococci, 4 with $S$. hemolysans, 7 with $S$. pyogenes aureus, 3 with $S$. pyogenes albus, 2 with gram-negative staining bacillus, and 1 with $B$. pyocyaneus, which happened to be present in the sputum in pure culture. 
Therefore, in this group of cases the treatment of the patients who were relieved and who were markedly improved shows the specificity of bacteria in the treatment of bronchial asthma in that only one of many kinds of vaccines gave good results. The failure in treatment in the sixteen cases, although a wide range of bacteria were used in the vaccines, shows that nonspecific vaccine treatment is not beneficial in bronchial asthma.

Table 2 gives the age of onset and the duration of asthma in the thirty-five patients who were treated with many types of vaccines.

TABLE 2.-Results of Treatment with Various Types of Vaccines

\begin{tabular}{|c|c|c|c|c|c|c|c|c|}
\hline \multicolumn{3}{|c|}{ Relieved of Asthma } & \multicolumn{3}{|c|}{ Markedly Improved } & \multicolumn{3}{|c|}{ Not Beneflted } \\
\hline $\begin{array}{c}\text { Number } \\
\text { of } \\
\text { Patients }\end{array}$ & $\begin{array}{l}\text { Age of } \\
\text { Onset, } \\
\text { Years }\end{array}$ & $\begin{array}{c}\text { Duration } \\
\text { of Asthma, } \\
\text { Years }\end{array}$ & $\begin{array}{c}\text { Number } \\
\text { of } \\
\text { Patients }\end{array}$ & $\begin{array}{l}\text { Age of } \\
\text { Onset, } \\
\text { Years }\end{array}$ & $\begin{array}{l}\text { Duration } \\
\text { of Asthma, } \\
\text { Years }\end{array}$ & $\begin{array}{c}\text { Number } \\
\text { of } \\
\text { Patients }\end{array}$ & $\begin{array}{l}\text { Age of } \\
\text { Onset, } \\
\text { Years }\end{array}$ & $\begin{array}{c}\text { Duration } \\
\text { of Asthma, } \\
\text { Years }\end{array}$ \\
\hline 1 & 1 & 11 & & & & 1 & 5 & 25 \\
\hline 1 & 2 & 4 & $\vdots$ & & & 1 & 6 & 9 \\
\hline 1 & 7 & 2 & 1 & 6 & 37 & 1 & 6 & $5 \tilde{j}$ \\
\hline 1 & 8 & 13 & 1 & 8 & 30 & 1 & 7 & 9 \\
\hline 1 & 13 & $3 i$ & 1 & 10 & 40 & 1 & 16 & 4 \\
\hline 1 & 18 & 20 & & & & 1 & 16 & 15 \\
\hline 1 & 19 & 24 & & & & 1 & 31 & 4 \\
\hline 1 & 20 & 22 & 1 & 21 & 8 & 1 & 34 & 2 \\
\hline 1 & 24 & 14 & $\mathbf{1}$ & 35 & 3 & 1 & 35 & 3 \\
\hline 1 & 26 & 1 & 1 & 36 & 2 & 1 & $3 \tilde{5}$ & 13 \\
\hline \multirow[t]{5}{*}{1} & 34 & 5 & 1 & 50 & 5 & 1 & 35 & 17 \\
\hline & & & 1 & 55 & 9 & 1 & 36 & 6 \\
\hline & & & & & & 1 & 40 & 6 \\
\hline & & & & & & 1 & 57 & 2 \\
\hline & & & & & & 1 & 60 & 1 \\
\hline
\end{tabular}

In Table 2 it is noted that although the duration of asthma in the cases not benefited averages considerably less than the duration in the relieved cases, the age of onset of asthma, and consequently the age of the patient when treated, averaged much greater in the not benefited patients than in the relieved cases. Therefore, the large percentage of failures in the vaccine treatment in this group of cases, in spite of the fact that a wide range of vaccines including the predominating organism as well as others were used, was probably due to the more advanced age of the patient both when asthma began and when treatment was instigated.

Nonsensitive summer asthmatics treated with vaccines.- Since it is generally believed that the type of asthma which is limited to the 
summer months is caused by pollens, it seems advisable to discuss briefly the following sixteen patients who were not sensitive to pollens although their attacks of asthma closely paralleled the pollination of plants. Of five patients who had had asthma all summer for five or more summers, with no asthma at other times of the year, and who would be considered sensitive to both the early and the late pollens, although they were not sensitive at all to pollens, two were relieved of asthma by vaccines of streptococci which predominated in their sputum when cultured in dextrose bouillon. One of these patients was not benefited by vaccines made from growing the sputum on plain agar, although she was relieved for two successive summers by streptococcus vaccines. A third patient was relieved by vaccines of $S$. pyogenes albus for two successive summers; this organism was used in the vaccine because it was present in the patient's nasal secretion in pure culture, and his nasal secretion was troublesome. The other two patients were not benefited by vaccines consisting of $S$. pyogenes aureus, S. pyogenes albus or diphtheroids. Two patients who had asthma only during June and July, the early pollen season, were not sensitive to pollens. One patient was relieved by vaccines of $S$. pyogenes aureus and the other patient was relieved for two successive summers by vaccines of $S$. pyogenes albus; the latter patient had had asthma for sixteen successive seasons. Three patients who had asthma only during July and August were not treated, because of the short duration of their attacks, and, furthermore, these untreated patients served as controls for the treated patients. Five patients had asthma during June, July and August. One patient was improved one summer by diphtheroid vaccines and was relieved the next summer by streptococcus vaccines; another patient was markedly improved by streptococcus vaccines; another patient was not benefited one summer by vaccines made from growing the sputum on plain agar, but was markedly improved the next summer by $S$. hemolysans vaccine; another patient was somewhat benefited one year by plain agar vaccines and another year by dextrose bouillon vaccines, but neither type of vaccines gave marked relief; the fifth patient was not benefited at all by streptococcus vaccine. Therefore, of sixteen nonesensitive summer asthmatics who were given vaccines, five were relieved of asthma, four were markedly improved, four were not benefited and three were not treated.

The following comparisons as regards treatment may be made between sensitive and nonsensitive asthmatic patients. In the previous article, which concerned patients sensitive to proteins, and in the first part of this article which concerns patients sensitive to bacterial proteins, it was shown that in general a favorable prognosis could be 
anticipated irrespective of the age of onset of asthma or the age of the patient when treated. With the nonsensitive patients, however, the later the age of onset and the later the age of the patient when treatment is begun, the more unfavorable the prognosis. The duration of asthma alone played little part in the prognosis in either type of case. Seventy-five per cent. of the sensitive patients were relieved of asthma by treatment with the proteins to which they were sensitive, whereas only 40 per cent. of the nonsensitive patients were relieved of asthma by treatment with vaccines. The permanency of relief from asthma in the sensitive patients was of much longer duration than in the nonsensitive patients. Both the sensitive and the nonsensitive patients illustrate specificity in the treatment of bronchial asthma; that is, the specificity of proteins in the treatment of sensitive cases and the specificity of bacteria in the treatment of nonsensitive cases. We have, however, only inferred that nonsensitive asthmatic patients are not benefited by treatment with proteins. Because of the more or less general belief that infections may be alleviated by nonspecific protein therapy - and in the case of chronic arthritis this is frequently found to be true - it seems worth while to mention our results in the treatment of the infectious or nonsensitive type of bronchial asthma with proteins.

Many of the nonsensitive or infectious type of asthmatics have been treated with various proteins. Three patients who were in the hospital wards because they were having severe asthma every day were given, intravenously, typhoid vaccine without improvement in the asthmatic symptoms. A week later a larger dose was given without any benefit. After this the patients were given, subcutaneously, two hundred million autogenous streptococcus vaccine made from growing their sputum in dextrose bouillon. A few days later one patient was somewhat improved, another seemed a little better and the third was not improved. A week later still the autogenous vaccine was increased to 250 million and a few days after this one patient was very much better, another was considerably improved and the third was somewhat better. The autogenous vaccine was given each week with gradual improvement in each instance until two patients left the hospital three weeks later and the third patient was able to leave in five weeks. Therefore, the intravenous typhoid vaccine was followed by no benefit, whereas the autogenous streptococcus vaccine was followed by a gradual though distinct improvement. Several of the nonsensitive summer asthmatics and some of the other non-sensitive cases were given courses of treatment with various pollens without benefit. A few nonsensitive patients were given wheat proteins and a few were given large doses of peptone subcutaneously without benefit. This 
latter method of treatment is dangerous unless the patient is tested with peptone to rule out the possibility of his being sensitive to it. We feel that this fad of injecting patients with proteins to which they are not already sensitive is, in general, apt to be a mistake; the possibility of sensitizing patients to proteins, exclusive of typhoid vaccine, seems to outweigh the chance of improvement by such treatment.

In this work we have made our vaccines in different ways in the hope of making them more efficient. At first toluol was used as a preservative, but because of frequent, small, sore indurations at the site of inoculation, toluol was given up and 0.25 per cent. phenol was substituted; the phenol has been very satisfactory. For a long time we killed our vaccine by heating at $56 \mathrm{C}$. for two hours; lately, however, we have heated it at $56 \mathrm{C}$. for only three quarters of an hour and we are inclined to think better results follow the shorter heating. A leukocytic extract was also given with the vaccines without any beneficial effect; we have not given sensitized vaccine. Patients react differently to different amounts of vaccine; some patients will improve on small gradually increased amounts, whereas other patients do not improve until large amounts are given. Therefore, we now make two dilutions of each vaccine, one containing 1,000 million to the cubic centimeter, and the other containing 10,000 million to the cubic centimeter. The weaker vaccine is given first for several doses in rapidly increasing amounts in order to see how the patient reacts, and if neither beneficial nor unfavorable results follow, then the stronger vaccine is used, but if desirable results follow the weaker vaccine this is then given in gradually increased amounts at weekly intervals; the first dose is usually about 200 million. In the treatment of bronchial asthma we have given 3,700 doses of vaccine; that is to say, we have taken the trouble actually to count this number of injections and we do not know how many more we have given which we have not attempted to count. In only one instance did a really bad reaction result; that one patient had fever, general malaise and was in bed for two weeks; the vaccine proved to be sterile and the patient had no local reaction, therefore the patient was considered too susceptible for further treatment. Of the 3,700 doses of vaccine given, 800 were S. pyogenes aureus, 1,200 diphtheroids, 1,000 streptococcus and the remaining were miscellaneous vaccines.

\section{CONCLUSIONS}

Twenty-eight patients with bronchial asthma were treated with vaccines of the bacteria to which they were sensitive; 75 per cent. were relieved of asthma and 21 per cent. were improved. 
Seventy-five nonsensitive patients were treated with vaccines made from culturing their sputum on plain agar; the predominating organism was usually the one selected for treatment; 46.6 per cent. were relieved of asthma and 16 per cent. were improved.

Twenty-four nonsensitive patients were treated with vaccines made from culturing their sputum in dextrose bouillon and using only the streptococci; 37.5 per cent, were relieved of asthma and 25 per cent. were improved.

Thirty-five nonsensitive patients were treated with vaccines made from culturing the sputum both ways; in other words, many types of vaccines were used; 31.4 per cent. were relieved and 23 per cent. were improved.

Sixteen nonsensitive summer asthmatics were treated with vaccines; 31.2 per cent. were relieved and 25 per cent. were improved.

Therefore, of 150 nonsensitive asthmatics who were treated with vaccines 40 per cent. were relieved and 20 per cent. were improved; these results should be compared with the treatment of sensitive patients as reported in the previous article, 75 per cent. of whom were relieved, and in this article 75 per cent. of whom were relieved.

With the sensitive cases, the age of onset of asthma, the duration of asthma and the age of the patient when treated had little to do with the prognosis; however, with the nonsensitive cases these facts had much bearing on the prognosis; the older the patient is when asthma begins and the older he is when treatment is begun, the more unfavorable the prognosis from vaccines in nonsensitive cases.

The permanency of relief from vaccines in the nonsensitive cases depends on the individual's resistance to the bacteria in question; therefore, the duration of relief from asthma varies. Some patients continue free from asthma after vaccines are discontinued for many months, others for only a month or two, and some patients require the constant use of vaccines to be free from asthma. Succeeding courses of vaccine treatment, provided that there has been no change in the bacteria which are causing the relapse, seem to relieve more promptly than the first course of vaccine treatment; when a relapse is not relieved by a second course of vaccines which previously did relieve, other bacteria should be suspected as the cause of asthma and new vaccines should be made.

721 Huntington Avenue. 